\title{
Ocular trauma in patients presenting to Dhulikhel Hospital
}

\author{
Sthapit PR, Marasini S, Khoju U, Thapa G, Nepal BP
}

Department of Ophthalmology

Kathmandu University School of Medical Sciences

Dhulikhel Hospital, Dhulikhel, Nepal

Corresponding Author

Dr. Purnima Rajkarnikar Sthapit

Department of Ophthalmology

Kathmandu University School of Medical Sciences

Dhulikhel Hospital, Dhulikhel, Nepal

E-Mail: purnimark@gmail.com

Citation

Sthapit PR, Marasini S, Khoju U, Thapa G, Nepal BP. Ocular trauma in patients presenting to Dhulikhel Hospital.Kathmandu Univ Med J 2011;33(1)54-7.

\section{ABSTRACT \\ Background}

Ocular trauma is an important cause of blindness and ocular morbidity throughout the world. Prevalence studies help to define the target group, plan strategies and thereby lessen trauma related blindness in the country.

\section{Objective}

To identify the risk factors for ocular trauma, those at risk, describe the visual acuity at time of clinical presentation, and assess the nature and severity of ocular trauma in patients presenting to Dhulikhel Hospital's emergency department and eye OPD with ocular trauma.

\section{Methods}

It is a descriptive and prospective study of all the patients with ocular trauma presenting to Dhulikhel Hospital from December 2009 to December 2010. A complete history and detailed ophthalmologic evaluation was done and noted down.

\section{Results}

There were 112 subjects with ocular trauma. Mean age was $28.43 \pm 16.36$ years with a range of one year to 74 years. Males predominated with $72.3 \%$ frequency $(p<0.001)$. Incidence peaked in third decade of life $(p<0.01)$. Ocular trauma peaked in months of September and October. Presenting visual acuity better than 6/12 was noted in $83.9 \%$ of cases whereas $2.7 \%$ of cases had visual acuity of $<3 / 60$. Household $(56.3 \%, \mathrm{p}<0.001)$ was the commonest place of injury with wooden objects (19.6\%) being the commonest object of injury. Most of the injuries were mechanical (85.7\%, $p>0.001)$.

\section{Conclusion}

Blunt injuries were more common in young males. Household and workplace were common location of ocular injuries. Public awareness and strict legislation to use personal protective devices can help to reduce the occurrence of ocular injury.

\section{KEY WORDS}

blindness, corneal abrasion, mechanical injury, ocular trauma

\section{INTRODUCTION}

Ocular trauma is an important cause of blindness and ocular morbidity throughout the world. The available literature on ocular trauma mainly comes from the developed countries with modern facilities of management. In Nepal, with developing economy, poor health facilities and poor access to health care system, trauma is a significant cause of ocular morbidity. In studies conducted by Upadhyay $\mathrm{M}$ et al, the prevalence of ocular trauma was observed to be $0.7 \%{ }^{1}$ Nepal Blindness Survey conducted more than 20 years ago in 1981 had observed trauma related blindness at a prevalence of $2.4 \% .^{2}$ These types of studies are important to define the target groups for prevention and education on ocular trauma. There is paucity of studies on this topic from the non-urbanized areas of our country.

This study aims to identify the risk factors for ocular trauma, those at risk, describe the visual acuity at time of clinical presentation and assess the nature and severity of ocular trauma in patients presenting to Dhulikhel Hospital's emergency department and eye OPD with ocular trauma. It also aims to compare findings with those of previous studies. 


\section{METHODS}

In this descriptive and prospective study, all the patients with ocular trauma visiting eye Out Patient Department (OPD) and Emergency Department of Dhulikhel Hospital, Kathmandu University Hospital, Kavrepalanchowk district, Nepal, from December 2009 to December 2010 were included. Detailed histories of all 112 patients were taken including demographic data, mode of injury, type as well as object of injury. The time of injury and the time of presentation as well as the distance travelled to reach hospital was noted.

Mechanism of injury was categorized as mechanical, chemical or thermal. Mechanical injury was further classified according to 'Ocular Trauma Classification Group' by Kuhn and associates into closed globe and open-globe injury. ${ }^{3}$ Closed-globe injury was divided into contusion injury and superficial injury.

Complete ophthalmologic evaluation was done including presenting visual acuity, measured with internally illuminated Snellen's chart. Detailed anterior segment evaluation was done with slit lamp bimicroscopy (Topcon), which included an examination of the lids and adnexae (lacerations, abrasions and ecchymosis), conjunctiva (tear, hemorrhages, abrasions), cornea (foreign body, abrasion, laceration) anterior chamber (depth, reaction, hyphaemia), iris, pupil (size, shape, light reaction), lens (clarity, position), vitreous (hemorrhage, detachment, reaction) and fundus (hemorrhages, detachment). The posterior segment evaluation was done with direct or Indirect ophthalmoscopes (Heine and Volk 78D/90 D Aspheric Lens). In cases of blunt trauma which did not seem to be severe clinically, X-ray was ordered. CT scan was ordered in cases of penetrating injuries and in cases where $X$-ray findings were suggestive of further investigation. An ophthalmologist examined all the patients and appropriate intervention was taken (conventional, medical or surgical and referral when needed).

Data were analyzed using SPSS. Chi-square test was applied to test the results statistically with a p-value below 0.05 considered as statistically significant.

\section{RESULTS}

Over a period of one year, 112 cases presented with ocular trauma. Mean age was 28.43 years \pm 16.36 with a range of one year to 74 years. Male patients predominated with $72.3 \%(p<0.001)$. The incidence of ocular trauma peaked in the third decade of life $(p<0.01)$. Many patients $(60.7 \%)$ were from rural areas and rest from urban areas. Half of the patients $(50.9 \%)$ lived $<5$ miles from hospital but only $15.2 \%$ of them reached hospital within six hours of injury. Ocular trauma peaked in month of September and October as shown in Figure 1.

Regarding the laterality of eye involved, right eye (RE) was involved in 55 cases, left eye (LE) in 40 cases and both eyes (BE) in 17 cases. Presenting visual acuity (VA) better than $6 / 12$ was noted in 94 cases $(83.92 \%)$ whereas three cases (2.67\%) had VA of $<3 / 60$. VA of three children couldn't be assessed with Snellen's chart. All of them were found to have good fixation and light follow.

Irrespective of gender, household injuries $(56.3 \%, p<0.001)$ were the most common, followed by workplace injuries (17.9\%) and physical assault (15.2\%). Ocular injuries were more commonly caused by wooden objects (19.6\%), followed by fist injury (13.4\%). Another important cause of injury was welding arc (11.6\%) especially among engineering students. The other causes of injuries are summarized in Table 1.

\section{Table 1. Object of Injury}

\begin{tabular}{lll}
\hline Object of Injury & Frequency & Percent \\
\hline Glass & 2 & 1.8 \\
\hline Finger & 3 & 2.7 \\
\hline Chemical & 3 & 2.7 \\
\hline Insect Bite & 4 & 3.6 \\
\hline Metal & 6 & 5.4 \\
\hline Stone & 8 & 7.1 \\
\hline Vegetative & 11 & 9.8 \\
\hline Fall injury & 12 & 10.7 \\
\hline Dust & 13 & 11.6 \\
\hline Welding arc & 13 & 11.6 \\
\hline Fist & 15 & 13.4 \\
\hline Wood & 22 & 19.6 \\
\hline Total & 112 & 100.0 \\
\hline
\end{tabular}

Most of the injuries were mechanical (85.7\%, $p>0.001)$. Lid edema and ecchymosis (27\% and $24.10 \%)$ were the most common presentation out of which six had lid lacerations. Among them, one patient had tiger bite injury to lids with multiple lacerations, edema and ecchymosis. This patient was treated with repair surgery along with coverage of antibiotics and anti rabies vaccine. Fifty patients (44.64\%) presented with conjunctival injuries among which 18 of them had subconjunctival hemorrhage, nine had foreign body lodged in conjunctiva and one of them had conjunctival laceration. Twelve patients (10.71\%) presented with corneal foreign bodies, metallic foreign bodies being more common and six of them developed corneal ulcer. Summary of the ocular findings are outlined in Table 2.

\section{DISCUSSION}

Ocular trauma is a major cause of monocular blindness and visual impairment throughout the world. ${ }^{3}$ A higher incidence of eye injuries in male (72.3\%) irrespective of age is consistent with other studies. ${ }^{2,4-8}$ It is possible that the lower incidence among women may be due to their poorer access to care. However, this difference between 
Table 2. Summary of ocular findings

\begin{tabular}{|c|c|c|}
\hline Structure involved & No & Percentage \\
\hline Lids & 33 & $(29.46)$ \\
\hline Laceration & 6 & 18.18 \\
\hline Oedema and ecchymosis & 27 & 81.81 \\
\hline Conjunctiva & 50 & 44.64 \\
\hline Sub-conjunctival haemorrhage & 18 & 36.00 \\
\hline Laceration & 1 & 2.00 \\
\hline Foreign body & 9 & 18.00 \\
\hline Hyperaemia & 22 & 44.00 \\
\hline Cornea & 30 & 26.78 \\
\hline Foreign body & 12 & 40.00 \\
\hline Abrasion & 11 & 36.66 \\
\hline Ulcer & 6 & 20.00 \\
\hline Laceration & 1 & 3.33 \\
\hline Uvea & 5 & 4.46 \\
\hline Uveitis & 3 & 60.00 \\
\hline Iridodialysis \& sphincter tear & 1 & 20.00 \\
\hline Iris prolapse & 1 & 20.00 \\
\hline Lens & 3 & 2.67 \\
\hline Cataract & 2 & 66.66 \\
\hline Dislocation & 1 & 33.33 \\
\hline Vitreous & 1 & 0.89 \\
\hline Hemorrhage & 1 & 100.00 \\
\hline Chemical injury & 3 & 2.67 \\
\hline Thermal Injury & 13 & 11.60 \\
\hline
\end{tabular}

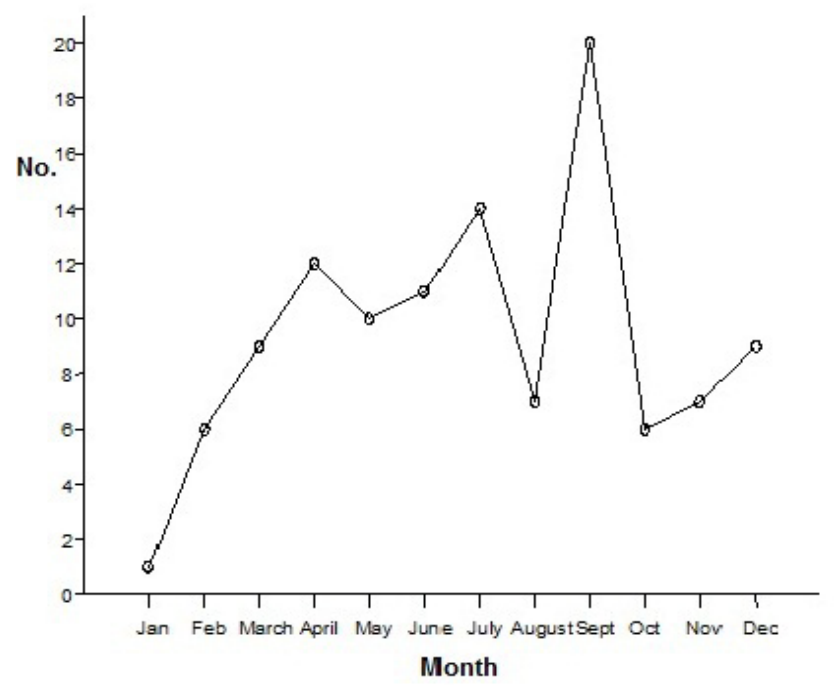

Figure 1. Month wise distribution of ocular trauma presenting to Dhulikhel Hospital- Kathmanadu University Hospital.

men and women is seen in many populations including the United States. ${ }^{4}$ So it is likely that this finding is due to the difference in exposure risk between men and women.

The age group more vulnerable to ocular trauma was 2130 years $(p<0.05)$. Second most common age group was $>40$ years old. This bimodal age pattern of ocular injury has been observed, with a peak in injury rates in young adults and people over 70 years of age in other studies as well. 5, 6, 9 Increased incidence of ocular injuries among young can be explained by their frequent social activity and the same in elderly population could be due to poor vision as a result of various ocular conditions like cataract, glaucoma, age related macular degeneration and previous ocular surgeries. ${ }^{6}$

Closed globe injuries predominated our study as only two patients sustained open globe injuries. Other studies also showed that closed globe injuries were six times higher than open globe injuries. ${ }^{9}$ In our study, the most common ocular injury documented was ocular contusion injury with lid edema, ecchymosis and subconjunctival hemorrhage followed by conjunctival foreign body, corneal abrasion and corneal foreign body. In studies conducted by Upadhyaya $\mathrm{M}$ et al in Bhaktapur and Oum BS et al in South Korea, corneal abrasion has been observed to be the most common finding. ${ }^{1,9}$

Most cases of microbial keratitis are reported to follow minor ocular trauma sustained during agricultural work or domestic activities and is a major cause of corneal scarring and visual loss in developing countries. Corneal opacity is second only to cataract as the most important cause of blindness worldwide. ${ }^{9}$ Wood stick was found to be most common object of injury in our study. Similar observations were noted in studies conducted in other parts of Nepal. ${ }^{10,}$ 11

There were 13 cases (11.60\%) of thermal injuries. All of them were engineering students from Kathmandu University who sustained welding arc injury. None of these patients gave history of wearing protective devices while working. Though there was a high risk of ocular injury in these occupations, the use of personal protective devices was totally absent in this group. The reason they gave for not wearing protective eye wear was their inexperience as they could not see through the protective dark glasses. Investigators believe that with education about and use of proper eye protection, $90 \%$ of eye injuries can be prevented. ${ }^{6}$

Ocular injuries are found to be most common in the household $(56.3 \%, \mathrm{p}<0.001)$. Adhikary RK note that in western Nepal, $55.5 \%$ of the children sustained trauma in the field and $26 \%$ at home. ${ }^{10}$ Similar observations were noted in Nepal Blindness Survey and in the studies by Khatri SK. ${ }^{2,4}$ This suggests the need for better monitoring of rural occupational injuries. The studies conducted in other countries like UK, South Korea and Turkey show that factory and workplace accidents are more common probably attributable to growing industrialization in those regions. ${ }^{9,12}$ Place of injury is significantly associated with age factor ( $p>0.001$ ) where young (21-30 year old) people were found to be injured more in the factory settings in these studies.

Ocular trauma peaked in early winter. Other peaks were seen in April and July as shown in figure 1. This is because 
of involvement of people in cutting foliage for their cattle and in wheat harvesting during the dry months of April, May and June. Similarly, early winter months are the time for rice harvesting. The two peaks of incidence of injury, in April and May (36/126, 28\%), and November and December (24/126, 19\%) was also seen in study conducted in western Nepal. ${ }^{10}$

Only $15.2 \%$ of patients presented within 6 hours of injury even though $50.9 \%$ of our patients lived $<5$ miles from the hospital. Most patients (54.5\%) presented within one day but after six hours. Some patients (10.7\%) patients presented after seven days. This late presentation could be because of distance from their home to nearest health facility as $13.4 \%$ of patients lived $>20$ miles away from hospital. The time of presentation with distance travelled is statistically significant $(p=0.001)$ showing that people from farther distances presented late. Another reason could be lack of health education and awareness among patients regarding grave outcome after ocular trauma because it appears trivial in the beginning. Among our patients more than $60 \%$ were from village where level of education is expected to be poor. They seek treatment in hospital when vision is badly affected. ${ }^{8}$ In our rural settings because of ignorance, lack of transportation facilities and lack of eye service facilities lots of patients are first seen by medical shop keepers, family members and traditional healers before coming to the hospital.

\section{CONCLUSION}

Blunt injuries were more common in young males. Household and workplace settings were common location of ocular injuries. Ocular trauma occurred most commonly in the third decade of life and in the elderly population, mechanical injuries and agricultural activities were the most common modes of trauma. Crop harvesting season was found to be the more vulnerable season. The planning of treatment and development of strategies should be done according to these findings to prevent ocular blindness due to trauma. Public awareness and strict legislation for the use of personal protective devices can also help reduce the occurrence of ocular injury.

\section{ACKNOWLEDGEMENT}

We would like to thank Mr. Seshananda Sanjel (MPH) for his assistance in statistical analysis and Dr. Anjana Shakya, MD (Pathology) for proof-editing this manuscript.

\section{REFERENCES}

1. M Upadhyay, P Karmacharya, S Koirala, D Shah, S Shakya, J Shrestha, H Bajracharya, C Gurung and J Whitcher. Bhaktapur eye study: ocular trauma and antibiotic prophylaxis for the prevention of corneal ulceration in Nepal. Br J Ophthalmol 2001;85:388-92.

2. Brilliant LB, Pokhrel RP, Grasset NC, Lepkowski JM, Kolstad A, Hawks W, Pakarajasegaram $R$ et al. Epidemiology of blindness in Nepal. Bulletin of the World Health Organization 1985;63(2):375-86.

3. Kuhn F, Morris R, Witherspoon D, et al. A standardized classification of ocular trauma. Ophthalmology 1996;103:240-3.

4. Khatry SK, Lewis AE, Schein OD, Thapa MD, Pradhan EK, Katz .The epidemiology of ocular trauma in rural Nepal. Br J Ophthalmol 2004;88:456-60.

5. Wong TY, Tielsch JM. A population-based study on the incidence of severe ocular trauma in Singapore. Am J Ophthalmol 1999;128(3):34551.

6. Mallika PS, Tan AK, Asok T, Faisal HA, Salowi MA, Intan G. Pattern of ocular trauma in Kuching, Malaysia. Malaysian Family Physician 2008;3:140-45.

7. Pandey PR. Study of Ocular Emergencies in Nepal Eye Hospital. PMJN 2009;24(9):2.

8. Dasgupta SS, Mukherjee RR, Ladi DS, Gandhi VH, Ladi BS. Pediatric ocular trauma-a clinical presentation. J Postgrad Med 1990;36(1):2022.

9. Oum BS, Lee JS, Han YS. Clinical Features of Ocular Trauma in Emergency Department. Korean J Ophthalmol 2004;18:70-78.

10. Adhikari RK, Pokhrel H, Chaudhary H, Chaudhary B. Ocular trauma among children in western Nepal: agents of trauma and visual outcome. Nep J Oph 2010;2(4):164-65.

11. Malla BK. Structural changes in ocular trauma and the visual outcome. KUMJ 2003;2(6):113-18.

12. Oner A, Kekec Z, Karakucuk S, Ikizceli, Sözüer EM. Ocular trauma in Turkey: A 2-year prospective study. Adv Ther 2006;23(2):274-80. 